\title{
STURKTUR DAN KAIDAH TEKS ANEKDOT DALAM KUMPULAN CERITA ABU NAWAS
}

\author{
Nazirun $^{1}$, Muhammad Mukhlis, ${ }^{2}$, Ermawati. $\mathrm{S}^{3}$ \\ Universitas Islam Riau, Pekanbaru, Indonesia ${ }^{1,2,3}$ \\ nazirun@edu.uir.ac.id ${ }^{1}, \underline{\text { m.mukhlis@edu.uir.ac.id }{ }^{2}, \text { ermawati.s@edu.uir.ac.id }{ }^{3}}$
}

\begin{abstract}
The background of the research was based on the existence of Abu Nawas stories that contain humor aspects. Besides, it has its uniqueness, so that readers are curious. The story of Abu Nawas is categorized as an anecdotal story because it contains the same structure and rules as the anecdotal text. Besides it also has a moral value so that it can be used as alternative teaching material at schools. Regarding the importance of Abu Nawas story, this study aimed to describe the structure and rules of anecdotal texts in the collection of Abu Nawas stories. This research was descriptive qualitative research. This research was conducted in literature. The research took six months. Data was collected using documentation techniques. This research data contained the text of the Abu Nawas anecdotal story containing structure and language use. The data analysis technique used in this study was the procedure and analysis model according to Miles and Huberman which consists of three stages, namely, data reduction, data presentation, and conclusion or verification. The results of this study, first, in terms of the generic structure, 44 anecdotal texts were perfect and 14 texts were not complete. It was proven by the average value which was $94 \%$ and was categorized complete based on the standard of anecdotal text structure covering abstract, orientation, crisis, reaction, and coda. Second, in terms of language use, 19 stories were complete and 39 stories did not use the language use properly. It was proven by the average value which was $75 \%$ and was categorized complete. The language features used in the form of past tense, rhetorical questions, temporal conjunction, material verbs, and imperative sentences.
\end{abstract}

Keywords: anecdote, Abu Nawas story, language use, structure

ABSTRAK

Penelitian dilatarbelakangi dengan adanya kumpulan cerita Abu Nawas yang mengandung unsur lucu atau humor. Selain itu, cerita tersebut memiliki keunikan tersendiri, sehingga membuat pembaca merasa penasaran terhadap ceritanya. Cerita Abu Nawas dikategorikan juga sebagai cerita anekdot, karena di dalamnya terkandung unsur struktur dan kaidah yang sama dengan teks anekdot. Pada sisi lain cerita tersebut juga memiliki pesan moral sehingga bisa dijadikan sebagai bahan ajar alternatif di sekolah. Berdasarkan hal tersebut penulis ingin mendeskripsikan lebih jauh tentang sturktur dan kaidah teks anekdot dalam kumpulan cerita Abu Nawas. Penelitian ini merupakan penelitian deskriptif dengan pendekatan kualitatif. Penelitian ini dilakukan di pustaka. Waktu penelitian selama enam bulan. Data dikumpulkan dengan menggunakan teknik dokumentasi. Data penelitian ini berupa teks cerita anekdot Abu Nawas yang mengandung struktur dan kaidah. Teknik analisis data yang digunakan dalam penelitian ini adalah prosedur dan model analisis menurut Miles dan Huberman yang terdiri atas tiga tahap.yaitu reduksi data (data reduction), 2. penyajian data (data display), dan 3. penarikan simpulan/verifikasi (coclusion drawing). Hasil penelitian ini ialah pertama, struktur teks anekdot pada cerita Abu Nawas terdapat 44 teks anekdot yang terbentuk dari struktur teks anekdot secara sempurna dan 14 data yang tidak memiliki struktur teks anekdot yang tidak sempurna. struktur teks anekdot pada cerita Abu Nawas diperoleh nilai rata-rata $94 \%$ memiliki struktur yang lengkap Struktur sempurna artinya teks anekdot tersebut terdiri dari abstraksi, orientasi, krisis, reaksi, dan koda sebagai pembentuk alur cerita suatu teks anekdot. Kedua, kaidah kebahasaan anekdot yang terdapat dalam Cerita Abu Nawas ditemui 19 data yang lengkap dan 39 data yang tidak lengkap. Kaidah kebahasaan teks anekdot pada kumpulan cerita Abu Nawas

Struktur dan Kaidah Teks Anekdot dalam Kumpulan Cerita Abu Nawas 
diperoleh nilai rata-rata $75 \%$ memiliki kaidah kebahasaan yang lengkap. Kaidah kebahasan tersebut berupa adanya waktu lampau, pertanyaan retorik, konjungsi temporal, kata kerja material, dan kalimat perinta.

\section{Kata Kunci: anekdot, cerita Abu Nawas, kaidah kebahasaan, struktur}

\section{PENDAHULUAN}

Anekdot diartikan sebagai cerita singkat yang menarik karena lucu dan mengesankan, biasanya mengenai orang-orang penting atau terkenal dan berdasarkan kejadian yang sebenarnya (Mukhlis dan Asnawi, 2019:31). Semantra itu, Dyah, Rustono, dan Nuryatin, (2017:69) mengatakan anekdot adalah cerita singkat yang menarik karena lucu dan mengesankan. Anekdot selalu dikaitkan dengan tanggapan terhadap feno-mena sosial. Sebuah anekdot merupakan sarana penyampaian pesan dan kritikan terhadap feno- mena sosial melalui kemasan cerita lucu namun sarat makna. Rasa peka terhadap fenomena yang terjadi di masyarakat sangat bagus sebagai materi pembelajaran Bahasa Indonesia bagi siswa di sekolah.

Senada dengan pendapat para ahli di atas, Kemendikbud dalam Oktarisa dkk (2014:2) teks anekdot ialah cerita singkat yang menarik karena lucu dan mengesankan, biasanya mengenai orang penting atau terkenal dan berdasarkan kejadian yang sebenarnya. Ada pengertian lain bahwa anekdot dapat merupakan cerita rekaan yang tidak harus didasarkan pada kenyataan yang terjadi di masyarakat. Yang menjadi partisipan atau pelaku di dalamnya pun tidak harus orang penting.

Berdasarkan pengertian tersebut, ada beberapa kriteria sebuah cerita disebut sebagai anekdot, yaitu: 1. Lucu atau menarik, 2. Mengesankan atau mengandung makna, 3. Tokohnya orang penting atau terkenal; dan 4. Kejadian nyata atau pernah terjadi baik pada masa lampau maupun pada masa kini. (Depdiknas, 2008:63). Hal senada juga disampaikan Wiranto dalam Mahsun (2014:25) bahwa anekdot merupakan satu jenis teks yang tergolong dalam genre cerita yang memiliki tujuan untuk menghibur serta dijadikan sebagai pembelajaran. Dalam teks anekdot peristiwa yang ditampilkan membuat pembaca merasa jengkel dan konyol.
Anekdot merupakan bagian dari wacana. Pemahaman pembaca mengenai pemakaian bahasa dapat menjadi titik singgung dalam analisis wacana. Dalam pandangan kritis, individu tidak dianggap sebagai subjek netral yang bisa menafsirkan secara bebas sesuai dengan pikirannya. Bahasa dalam pandangan kritis dipahami sebagai representasi yang berperan dalam membentuk subjek tertentu, tema wacana tertentu, maupun strategi yang ada di dalamnya. Bahasa mempunyai peranan yang sangat penting guna menuangkan ide pokok pikiran, baik dalam bentuk lisan maupun tulisan. Ketika seseorang mengemukakan gagasan, yang perlu diperhatikan bukan hanya kebahasaan melainkan juga harus ada pemahaman. Dengan adanya pemahaman, maksud dan tujuan pun akan tersampaikan secara jelas. Begitu juga dengan cerita $\mathrm{Abu}$ Nawas hendaknya bisa tersampaikan kepada pembaca.

Cerita Abu Nawas memiliki struktur dan kaidah yang sama dengan teks anekdot. Hal ini terlihat dari beberapa cerita yang dibacakan mengandung keseluruh ciri teks anekdot. Adapun ciri teks anekdot berdasarkan struktur menurut Yustinah (2014:4) ada lima yaitu abstrak, orientasi, krisis, reaksi, dan koda.

Hal senada juga disampaikan oleh Kosasih (2014:8) bahwa Struktur anekdot berupa cerita atau narasi singkat. Di dalamnya ada tokoh, alur, dan latar. (a) tokoh bersifat faktual, biasanya orang-orang terkenal (b) alur berupa rangkaian peristiwa yang benar-benar terjadi ataupun sudah mendapat polesan maupun tambahan-tambahan dari pembuat anekdot itu sendiri (c) latar berupa waktu, tempat, ataupun suasana dalam anekdot diharapkan bersifat faktual. Artinya benarbenar ada di dalam kehidupan yang sesungguhnya. (d) berupa lelucon ataupun cerita menggelitik dan (e) di dalamnya terkandung kebenaran tertentu yang bisa menjadi bahan pelajaran bagi khalayak.

Struktur dan Kaidah Teks Anekdot dalam Kumpulan Cerita Abu Nawas 
Selain itu, dari segi kebahasaan cerita

Abu Nawas memiliki kesamaan dengan teks anekdot. Hal ini sesuai dengan pendapat yang dikemukakan oleh Kemendikbud (2013:194) bahwa teks anekdot dari segi sturktur memiliki lima aspek yaitu Pertama, abstraksi yaitu berupa isyarat akan apa yang diceritakan berupa kejadian yang tidak lumrah, tidak biasa, aneh atau berupa rangkuman atas apa yang akan diceritakan atau dipaparkan teks. Kedua, orientasi yaitu pendahuluan atau pembuka berupa pengenalan tokoh, waktu dan tempat. Ketiga, krisis yaitu pemunculan masalah. Keempat, reaksi yaitu tindakan atau langka yang diambil untuk merespon masalah. Lima, koda yaitu perubahan yang terjadi pada tokoh dan pelajaran yang dapat dipetik dari cerita.

Cerita Abu Nawas bermula dari sebuah buku dongeng yang berjudul (cerita seribu satu malam). Abu Nawas dari literatur yang dibaca ialah seorang penyair pada zaman Bani Abbasiyyah. Nama asli beliau ialah Abu Ali Hasan bin Hani alHakimi. Cerita-cerita beliau banyak digemari oleh anak-anak. Hal ini karena lucu dan cerdiknya beliau dalam mengatasi masalah. Selain itu, bahasa yang dgunakan mudah dipahami dan tidak terlalu panjang setiap kisah-kisahnya. Selain itu, kisah-kisahnya terdapat nilai-nilai pendidikan yang dapat memberikan contoh kepada pembacanya.

Pada beberapa cerita Abu Nawas, banyak digunakan sebagai bahan ajar di sekolah terutama pada buku teks bahasa Indonesia di jenjang SLTA kurkulum 2013. Oleh karena itu, penulis mengkaji seluruh cerita Abu Nawas baik dari segi struktur maupun kaidah kebahasaan sesuia dengan ketentuan yang tetapkan dalam kurikulum 2013.

Struktur teks anekdot terdiri atas lima bagian yaitu abstract, orientation, crisis, reaction, dan coda. Anekdot yang terdiri dari lima unsur tersebut merupakan anekdot yang utuh. Dimungkinkan terdapat anekdot yang hanya terdiri dari tiga unsur, yaitu orientasi, krisis, dan reaksi. Dengan demikian, sebuah cerita anekdot minimal terdiri dari pendahuluan (orientasi), konflik (krisis), dan penutup (reaksi).
Sementara itu Sobandi (2013:2)

berpendapat, struktur anekdot itu terdiri dari tiga bagian yaitu: 1) tokoh, 2) alur, dan 3) latar.

1. Anekdot hanya menggunakan manusia sebagai tokoh, baik terkenal maupun tidak. Jumlahnya tidak beberapa; bisa juga satu orang. Tokoh tersebut dapat diindentifikasi karena bersifat faktual atau benar-benar ada, bukan tokoh fiktif dari khayangan atau para dewa.

2. Alur adalah rangkaian peristiwa atau urutan bagian-bagian dalam sebuah cerita. Anekdot umumnya menggunakan alur maju dan cepat selesai. Meskipun demikian, teks anekdot memiliki pengantar, bagian isi, dan bagian akhir yang mengentak (kelucuan).

3. Latar adalah segala keterangan yang berhubungan dengan waktu, tempat, dan suasana yang tergambar dalam cerita. Anekdot menggunakan latar tempat, waktu, dan suasana yang bersifat faktual atau sesuai dengan kehidupan sehari-hari.

Berdasarkan baca awal yang dilakukan, beberapa cerita Abu Nawas juga memiliki kesamaan struktur dengan teks anekdot. Namun, juga terdapat beberapa cerita yang tidak secara sempurna memiliki struktur teks anekdot tersebut.

Selanjutnya, selain struktur anekdot memiliki kaidah kebahasaan sendiri, yaitu (a) menggunakan kalimat yang menyatakan peristiwa masa lalu/waktu lampau, (b) menggunakan kalimat retoris/retorik (kalimat pertanyaan yang tidak membutuhkan jawaban, (c) menggunakan konjugsi temporal (kata penghubung yang menyatakan hubungan waktu seperti kemudian, lalu) (d) menggunakan kata aksi/kata kerja material seperti menulis, membaca,dan berjalan, (e) mengggunakan kalimat perintah (Kemendikbud, 2016:95). Lebih jelas mengenai ciri kebahasaan teks anekdot akan diuraikan berikut ini.

Pertama, menggunakan waktu lampau cerita-cerita dalam anekdot biasanya dimulai dengan kata kemarin, sejak dulu, sebermula, konon, suatu hari, dan sejenisnya. Kedua, menggunakan pertanyaan retorik, yaitu anekdot dibuat dengan pertanyaan-pertanyaan

Struktur dan Kaidah Teks Anekdot dalam Kumpulan Cerita Abu Nawas 
retorik, yaitu pertanyaan yang tidak membutuhkan jawaban. Dengan pertanyaan retorik, kesan lucu cerita anekdot dapat terasa.Contoh-contoh pertanyaan retorik: Mengapa jadi begini ? Menangiskah ia ?

Ketiga, menggunakan konjungsi temporal atau kata sambung aksi yaitu teks anekdot tidak terlepas dari kata sambung atau konjungsi, konjungsi digunakan untuk menghubungkan kata-kata, frasa-frasa, kalimat-kalimat, kata dan frasa, frasa dan kalimat, atau kalimat dan paragraf. Tanpa konjungsi, paragraf demi keempat, menggunakan kata kerja material yaitu anekdot disusun dengan menggunakan verba atau kata kerja. Hal ini dimaksudkan agar aktivitas atau kegiatan terlihat dengan jelas. Kelima, menggunakan kalimat perintah yaitu anekdot dibuat dengan kalimat perintah untuk memudahkan pemahaman strukturnya.

Berdasarkan kaidah kebahasaan tersebut beberapa judul cerita tentang Abu Nawas memiliki kesamaan. Hal ini berdasarkan temuan awal ketika membaca cerita tersebut. Beberapa cerita memenuhi keselurahan kaidah kebahasaan, sedangkan beberapa cerita tidak secara keseluruhan memenuhi kriteria. Oleh karena itu, untuk membuktikan pemenuhan kaidah tersebut diperlukan penelitian secara mendalam tentang kaidah dan struktur teks Anekdot.

\section{METODOLOGI PENELITIAN}

Penelitian ini merupakan penelitian deskriptif dengan pendekatan kualitatif. Penelitian ini dilakukan di pustaka. Waktu penelitian selama enam bulan. Teknik yang digunakan untuk mengumpulkan data adalah dengan teknik dokumentasi (Heryadi, 2010:42). Sumber data yang digunakan dalam peneilitian ini ialah kumpulan cerita Abu Nawas yang terdapat dalam buku online. adapun kisah yang diceritakan berjumlah 58 judul. Data penelitian ini adalah seluruh struktur dan kaidah teks anekdot yang terdapat dalam kumpulan cerita Abu Nawas.

Teknik analisis data yang digunakan dalam penelitian ini adalah prosedur dan model analisis menurut Miles dan Huberman dalam (Sugiyono, 2008) yang terdiri atas tiga tahap. Tiga tahap tersebut yaitu 1. reduksi data, 2. penyajian data, dan 3. penarikan simpulan/verifikasi. Pertama, reduksi data (data reduction) dilakukan dengan memilih hal-hal pokok, memfokuskan pada hal-hal penting, mencari polanya dan membuang yang tidak perlu. Adapun hal-hal yang dilakukan pada tahap ini, yaitu: (1) Membaca secara mendalam setiap kisah yang terdapat dalam kumpulan cerita Abu Nawas. (2) Memilih data dalam kumpulan cerita Abu Nawas; (3) Menganalisis struktur teks anekdot yang terpilih; (4) Menganalisis kaidah seluruh teks anekdot terpilih. Kedua, penyajian data (data display), dilakukan dengan mengolah dan menganalisis data untuk memperoleh jawaban yang tepat dan sesuai dengan rumusan masalah. Data yang telah dianalisis dalam penelitian ini diuraikan sedemikian rupa dan dihubungkan dengan teori-teori yang relevan sehingga permasalahan dalam penelitian ini terjawab. Ketiga, penarikan simpulan/verifikasi (conclusion drawing), pembuatan simpulan adalah jawaban dari permasalahan yang sesuai dengan keadaan dan apa adanya. Hasil penelitian ini secermat mungkin dikaji sehingga bisa memperoleh simpulan yang tepat.

\section{HASIL DAN PEMBAHASAN}

Pada bagian ini penulis akan menguraikan hasil dan pembahasan berdasarkan permasalahan yang dikemukakan sebelumnya. Adapun permasalahan yang dikemukakan ialaha mengenai struktur dan kaidah yang terdapat pada cerita Abu Nawas.

\section{Struktur Teks Anekdot dalam Kumpulan Cerita Abu Nawas}

Struktur teks anekdot terdiri dari lima aspek. Aspek tersebut berupa abstraksi, orientasi, krisis, reaksi, dan koda. Berdasarkan keseluruhan aspek tersebut ditemukan beberapa kesamaan dari cerita Abu Nawas. Adapun hasil penelitiannya adalah sebagai berikut ini.

Berdasarakan 58 judul cerita Abu Nawas, diketahui struktur teks anekdot bagian abstraksi terdapat 49 data dan 9 data yang tidak terdapat abstraksi. Struktur teks anekdot bagian orientasi terdapat 58 data. Struktur teks anekdot bagian krisis terdapat 55 data dan 3

Struktur dan Kaidah Teks Anekdot dalam Kumpulan Cerita Abu Nawas 
data yang tidak terdapat krisis. Struktur teks anekdot bagian reaksi terdapat 55 data dan 3 data yang tidak terdapat reaksi. Struktur teks anekdot bagian koda terdapat 55 data dan 3 data yang tidak terdapat koda. Salah satu analisisnya ialah berikut ini.

Pertama struktur yang berkaitan dengan abstraksi terdapat pada data 1 dengan judul cerita "Telur Beranak: Menipu Balik Tuan Tanah". pada bagian ini terdapat gambaran awal tentang isi dari teks anekdot yang di dalamnya menceritakan secara singkat tokoh utama yaitu "Abu Nawas" dan menjelaskan tentang awal mula cerita. Jumlah cerita Abu Nawas yang terdapat Abstraksi berjumlah 49 data. Pada cerita 1 abstraksi terdapat pada kutipan data berikut ini.

Abu Nawas memiliki tetangga yang sangat kikir dan serakah, dia pun ingin memberikan pelajaran agar tetangga yang berprofesi sebagai tuan tanah tersebut bertobat. Bagaimana kisahnya $y a$,

Selanjutnya, struktur Anekdot pada bagian abstraksi tidak terdapat dalam beberapa data berikut. Adapun judul cerita yang tidak terdapat abstraksi yaitu pada data 10 dengan judul cerita "Abu Nawas Taruhan Berbahaya"

Data 13 dengan judul cerita "Cara BerkebunAbu Nawas", data 14 dengan judul cerita "Abu Nawas Raja Jadi Budak", data 16 dengan judul cerita "Abu Nawas Pintu Akhirat", data 17 dengan judul cerita "Cara Menyadarkan pengemis", data 19 dengan judul cerita "Abu Nawas Akan dihukum Pancung", data 34 dengan judul cerita "Tertipu Sendal ajaib", data 35 dengan judul cerita "Abu Nawas hadiah Tembakan Jitu", dan data 36 dengan judul cerita "Selamatkan Raja dengan Sorban using".

Kedua, struktur teks anekdot berikutnya adalah yang berkaitan dengan orientasi. Orientasi merupakan bagian cerita yang mengarah pada terjadinya suatu krisis, konflik, atau peristiwa utama. Bagian inilah yang menyebabkan timbulnya krisis. Pada bagian inilah awal kejadian cerita atau latar belakang bagaimana peristiwa terjadi. Biasanya penulis bercerita dengan detail pada bagian ini. Jumlah cerita Abu Nawas yang terdapat orientasi berjumlah 58 data. Pada cerita 1 orientasi terdapat pada kutipan data berikut ini.

Pada suatu sore, Abu Nawas duduk di beranda rumahnya sambil memandang langit. Abu Nawas berpikir bagaimana caranya agar sore itu keluarganya bisa dapat makan. Sementara itu, dalam jarak puluhan meter dari rumah Abu Nawas, seorang tuan tanah tinggal. Rumahnya mewah, lengkap dengan gudang makanan dan peternakan serta perkebunan yang luas.

Ketiga, struktur selanjutnya yang terdapat dalam teks anekdot adalah krisis. Krisis atau komplikasi merupakan bagian dari inti peristiwa suatu anekdot. Pada bagian itulah adanya kekonyolan yang menggelitik dan mengundang tawa serta biasanya mengandung hal unik yang tidak biasa terjadi. Teks anekdot bagian krisis terdapat 55 data. Dari data 1 terdapat masalah unik dan lucu yang menimbulkan gelak tawa si pembaca. Hal ini terdapat pada kutipan data berikut ini.

Tuan tanah itu mendengar berita bahwa Abu Nawas memiliki keahlian yang unik.Apabila meminjam sesuatu akan dikembalikan secara lebih dengan alasan beranak. Seperti meminjam seekor ayam, maka akan dikembalikan dua karena ayam itu beranak. Tuan tanah lalu mencari cara agar Abu Nawas segera meminjam uang darinya.

Keempat, Struktur salanjutnya dalam teks anekdot adalah yang berkaitan dengan reaksi. Reaksi merupakan tanggapan atau respons atas krisis yang dinyatakan sebelumnya. Reaksi yang dimaksud dapat berupa sikap mencela atau menertawakan. Cerita Abu Nawas yang terdapat orientasi berjumlah 55 data. Pada cerita 1 reaksi terdapat pada kutipan data berikut ini.

Karena tidak sabar, si tuan tanah mendatangi Abunawas dengan didampingi pengawalnya. Mulanya si tuan tanah gembira, namun dia marah besar setelah menerima penjelasan dari Abu Nawas. "Sayang sekali Tuan, uang yang saya pinjam, bukannya beranak, malah tiga hari setelah saya bawa pulang, mati mendadak," ujar Abu

Struktur dan Kaidah Teks Anekdot dalam Kumpulan Cerita Abu Nawas 
Nawas. Mendengar itu, si tuan tanah menjadi geram.Pengawalnya hampir saja memukul Abu Nawas, tapi untung saja tidak jadi karena ada rombongan pekerja yang baru pulang. Tuan tanah mengadukan Abu Nawas ke pengadilan dan berharap Abunawas digantung atau bahkan dihukum rajam.

Selanjutnya, struktur Anekdot pada bagian Reaksi tidak terdapat dalam beberapa data berikut. Adapun judul cerita yang tidak terdapat Reaksi yaitu pada data 25 dengan judul cerita "Abu Nawas Orang Kanibal", data 30 dengan judul cerita "Lomba Mimpi di Bulan Ramadan", dan data 33 dengan judul cerita "Abu Nawas Ibu Sejati".

Kelima, Struktur berikutnya yang terdapat dalam teks anekdot adalah koda. Koda merupakan bagian akhir dari cerita unik tersebut. Bisa juga dengan memberikan simpulan tentang kejadian yang dialami penulis atau yang ditulis. Cerita Abu Nawas yang terdapat koda berjumlah 55 data. Pada cerita 1 orientasi terdapat pada kutipan data berikut ini.

Di depan hakim, Abu Nawas melakukan pembelaan dengan membeberkan semua duduk persoalannya. Demikian juga dengan si tuan tanah. Pengadilan pun memutuskan bahwa Abu Nawas tidak bersalah karena sangat masuk akal kalau sesuatu yang bisa beranak pasti bisa mati. Seketika itu juga tuan tanah yang tamak itu pingsan selama beberapa jaman sulit untuk dibangunkan. Ia telah tertipu karena wataknya sendiri yang kikir, tamak dan pelit.

Selanjutnya, struktur Anekdot pada bagian Koda tidak terdapat dalam beberapa data berikut. Adapun judul cerita yang tidak terdapat Koda yaitu pada data 23 dengan judul cerita "Abu Nawas Pekerjaan Mustahil", data 25 dengan judul cerita "Abu Nawas Orang Kanibal", dan data 30 dengan judul cerita "Lomba Mimpi di Bulan Ramadan". Lebih jelas tentang struktur teks anekdot pada cerita Abu Nawas akan diuraikan dalam bentuk tabel persentase berikut ini.
Tabel 1. Rekapitulasi Struktur Teks Anekdot Pada Cerita Abu nawas

\begin{tabular}{|c|c|c|}
\hline No & $\begin{array}{ll}\text { Struktur } & \text { Teks } \\
\text { Anekdot } & \\
\end{array}$ & Presentasi \\
\hline 1. & Abstraksi & $84 \%$ \\
\hline 2. & Orientasi & $100 \%$ \\
\hline 3. & Krisis & $95 \%$ \\
\hline 4. & Reaksi & $95 \%$ \\
\hline 5. & Koda & $95 \%$ \\
\hline \multicolumn{2}{|r|}{ Rata-rata } & $94 \%$ \\
\hline
\end{tabular}

Berdasarkan tebel rekapitulasi struktur teks anekdot pada cerita Abu Nawas di atas diperoleh nilai rata-rata $94 \%$ seluruh cerita Abu Nawas memiliki Struktur yang lengkap. Pada bagian abstraksi diperoleh nilai 84\%, bagian orientasi diperoleh nilai $100 \%$, bagian krisis diperoleh nilai 95\%, bagian reaksi diperoleh nilai $95 \%$ dan bagian koda diperoleh nilai $95 \%$.

\section{Kaidah Kebahasaan Teks Anekdot Pada Cerita Abu Nawas}

Kaidah kebahasaan teks anekdot terdiri dari lima aspek. Aspek tersebut berupa Waktu lampau, pertanyaan retorik, konjungsi temporal, kata kerja material, dan kalimat perintah. Berdasarkan keseluruhan aspek tersebut ditemukan beberapa kesamaan dari cerita Abu Nawas dan ada juga yang tidak memenuhi. Adapun hasil penelitiannya adalah sebagai berikut ini

Berdasarkan 58 judul cerita Abu nawas, diketahui kaidah kebahasaan teks anekdot bagian waktu lampau terdapat 46 data dan 12 data yang tidak terdapat waktu lampau. Kaidah kebahasaan teks anekdot bagian pertanyaan retorik terdapat 30 data dan 28 data yang tidak terdapat pertanyaan retorik. Kaidah kebahasaan teks anekdot bagian konjungsi temporal terdapat 57 data dan 1 data yang tidak terdapat konjungsi temporal. Kaidah kebahasaan teks anekdot bagian kata kerja material terdapat 50 data dan 8 data yang tidak terdapat kata kerja material. Kaidah kebahasaan teks anekdot bagian kalimat perintah terdapat 36 data dan 22 data yang tidak terdapat kalimat perintah.

Kaidah kebahasaan pada teks anekdot diantarany ialah penggunaan waktu lampau,

Struktur dan Kaidah Teks Anekdot dalam Kumpulan Cerita Abu Nawas 
menggunakan pernyataan retorik,

menggunakan konjungsi temporal, menggunakan kata kerja material, dan menggunakan kalimat perintah. Pada data 1 dengan judul "Telur Beranak: Menipu Balik Tuan Tanah" terdapat kaidah kebahasaan anekdot. Kaidah tersebut diantarany ialah penggunaan waktu lampau, menggunakan konjungsi temporal, dan menggunakan kata kerja material. Pertama, penggunaan waktu lampau juga terdapat dalam cerita 1. Hal ini ditandai dengan kata kemarin, sejak dulu, konon, suatu hari dan sejenisnya. Hal ini terdapat pada kutipan data 1 berikut ini.

Pada suatu sore, Abu Nawas duduk di beranda rumahnya sambil memandang langit. Abu Nawas berpikir bagaimana caranya agar sore itu keluarganya bisa dapat makan.

Selanjutnya, struktur Anekdot pada bagian kaidah kebahasaan waktu lampau tidak terdapat dalam beberapa data berikut. Adapun judul cerita yang tidak terdapat penggunaan waktu lampau yaitu pada data data 6 dengan judul cerita "Abu Nawas Tipu Menipu", data 14 dengan judul cerita "Abu Nawas Raja Jadi Budak", data 16 dengan judul cerita "Abu Nawas Pintu Akhirat", data 19 dengan judul cerita "Abu Nawas Akan dihukum Pancung", data 20 dengan judul cerita "Abu Nawas Selamat Dari Amarah istri", data 23 dengan judul cerita "Abu Nawas Pekerjaan Mustahil", data 25 dengan judul cerita "Abu Nawas Orang Kanibal", dan data 29 dengan judul cerita "Abu Nawas Manusia Bertelur", data 33 dengan judul cerita "Abu Nawas Ibu Sejati", data 34 dengan judul cerita "Tertipu Sendal ajaib", data 35 dengan judul cerita "Abu Nawas hadiah Tembakan Jitu", data 36 dengan judul cerita "Selamatkan Raja dengan Sorban using"

Kedua, anekdot dibuat dengan menggunakan pertanyaan-pertanyaan retorik, yaitu pertanyaan yang tidak membutuhkan jawaban. Dengan pertanyaan retorik, kesan lucu cerita anekdot dapat terasa. Dalam data 4 dengan judul cerita "Abu Nawas Tugas Mustahil" terdapat 1 penggunaan pertanyaan retorik. Hal ini terdapat pada kutipan berikut ini.
Baginda Raja girang bukan kepalang.

Benarkah Abu Nawas berhasil membangun istana di langit? Dengan tidak sabar beliau didampingi beberapa orang pengawal bergegas menemui Abu Nawas.

Selanjutnya, struktur Anekdot pada bagian kaidah kebahasaan pertanyaan retorik tidak terdapat dalam beberapa data berikut. Adapun judul cerita yang tidak terdapat penggunaan pertanyaan retorik yaitu pada data 1 dengan judul cerita "Telur Beranak: Menipu Balik Tuan Tanah", data 2 dengan judul cerita "Abu Nawas Mengoceh Raja", data 3 dengan judul cerita "Hukum Berdasarkan Mimpi”, data 5 dengan judul cerita "Istana Raja Hancur Karena Lalat", data 6 dengan judul cerita "Abu Nawas Tipu Menipu", data 7 dengan judul cerita "Mengobati Sakit dengan Telur Unta", data 9 dengan judul cerita "Abu Nawas Dua Kali Terbebas dari Kematian", data 10 dengan judul cerita "Abu Nawas Taruhan Berbahaya", Data 13 dengan judul cerita "Cara BerkebunAbu Nawas", data 14 dengan judul cerita "Abu Nawas Raja Jadi Budak", data 15 dengan judul cerita "Sindiran Abu Nawas Kepada penjabat Pemerintah", data 16 dengan judul cerita "Abu Nawas Pintu Akhirat", data 17 dengan judul cerita "Cara Menyadarkan pengemis", data 20 dengan judul cerita "Abu Nawas Selamat Dari Amarah istri”, data 21 dengan judul cerita "Abu Nawas Peringan aneh", data 22 dengan judul cerita "Membalas Tipuan Sang Hakim", data 23 dengan judul cerita "Abu Nawas Pekerjaan Mustahil", data 24 dengan judul cerita "Raja Disuruh Mencium Pantat Ayam", data 25 dengan judul cerita "Abu Nawas Orang Kanibal", data 26 dengan judul cerita "Menipu Komandan Kerajaan", data 27 dengan judul cerita "Abu Nawas Menjebak Pencuri", data 28 dengan judul cerita "emilih Jalan Kehutan yang Indah", data 29 dengan judul cerita "Abu Nawas Manusia Bertelur", data 32 dengan judul cerita "Raja Nyaris terbunuh", data 33 dengan judul cerita "Abu Nawas Ibu Sejati", data 34 dengan judul cerita "Tertipu Sendal ajaib", data 35 dengan judul cerita "Abu Nawas hadiah Tembakan Jitu", dan data 36

Struktur dan Kaidah Teks Anekdot dalam Kumpulan Cerita Abu Nawas 
dengan judul cerita "Selamatkan Raja dengan Sorban using".

Ketiga, Teks anekdot tidak terlepas dari kata sambung atau konjungsi. Konjungsi yang digunakan yaitu konjungsi yang menyatakan hubungan waktu seperti, kemudian, lalu, akhirnya, ketika, setelah, selanjutnya, dll. Dalam data 1 terdapat penggunaan konjungsi. Hal ini terdapat pada kutipan berikut ini.

Abu Nawas memiliki tetangga yang sangat kikir dan serakah, dia pun ingin memberikan pelajaran agar tetangga yang berprofesi sebagai tuan tanah tersebut bertobat. Rumahnya mewah, lengkap dengan gudang makanan dan peternakan serta perkebunan yang luas. Walaupun tidak sesuai dengan yang diharapkan, tetapi hati si Tuan tanah cukup gembira.

Selanjutnya, struktur Anekdot pada bagian kaidah kebahasaan konjungsi temporal tidak terdapat dalam beberapa data berikut. Adapun judul cerita yang tidak terdapat penggunaan konjungsi temporal yaitu pada data 27 dengan judul cerita "Abu Nawas Menjebak Pencuri”.

Keempat, anekdot disusun dengan menggunakan verba atau kata kerja yang menandakan suatu aksi atau tindakan, contohnya berjalan, menulis, membaca, makan, naik, dll. Hal ini dimaksudkan agar aktivitas atau kegiatan terlihat dengan jelas. Dalam data 1 terdapat penggunaan kata kerja material. Hal ini terdapat pada kutipan berikut ini.

Abu Nawas duduk di beranda rumahnya sambil memandang langit. Abu Nawas berpikir bagaimana caranya agar sore itu keluarganya bisa dapat makan.

Selanjutnya, struktur Anekdot pada bagian kaidah kebahasaan kata kerja material/aksi tidak terdapat dalam beberapa data berikut. Adapun judul cerita yang tidak terdapat penggunaan kata kerja material yaitu pada data 21 dengan judul cerita "Abu Nawas Peringan aneh", data 22 dengan judul cerita "Membalas Tipuan Sang Hakim", data 25 dengan judul cerita "Abu Nawas Orang
Kanibal", data 26 dengan judul cerita "Menipu Komandan Kerajaan", data 27 dengan judul cerita "Abu Nawas Menjebak Pencuri", data 28 dengan judul cerita "emilih Jalan Kehutan yang Indah", data 29 dengan judul cerita "Abu Nawas Manusia Bertelur", dan data 55 dengan judul cerita "Abu Nawas Merayu Tuhan".

Kelima, anekdot dibuat dengan menggunakan kalimat perintah untuk memudahkan pemahaman strukturnya. Kalimat perintah merupakan kalimat yang mengandung makna meminta/ memerintah seseorang untuk melakukan sesuatu. Arti Kalimat perintah adalah kalimat yang isinya menyuruh orang lain untuk melakukan sesuatu yang kita kehendaki. Pada data 2 dengan judul cerita "Abu Nawas Mengoceh Raja" terdapat kalimat yang merupakan kalimat perintah. Hal ini terdapat pada kutipan berikut ini.

"Hamba sebenarnya tidak melarikan diri dari hujan.Tetapi begitu hujan turun hamba secepat mungkin melepas pakaian hamba dan segera melipatnya, lalu mendudukinya. Ini hamba lakukan sampai hujan berhenti." Diam-diam Baginda Raja mengakui kecerdikan Abu Nawas.

Selanjutnya, struktur Anekdot pada bagian kaidah kebahasaan kalimat perintah tidak terdapat dalam beberapa data berikut. Adapun judul cerita yang tidak terdapat penggunaan kalimat perintah yaitu pada data 1 dengan judul cerita "Telur Beranak: Menipu Balik Tuan Tanah", data 6 dengan judul cerita "Abu Nawas Tipu Menipu", data 8 dengan judul cerita "Abu Nawas tetap Bisa Cari Solusi", Data 13 dengan judul cerita "Cara BerkebunAbu Nawas", data 16 dengan judul cerita "Abu Nawas Pintu Akhirat", data 17 dengan judul cerita "Cara Menyadarkan pengemis", data 20 dengan judul cerita "Abu Nawas Selamat Dari Amarah istri", data 22 dengan judul cerita "Membalas Tipuan Sang Hakim", data 23 dengan judul cerita "Abu Nawas Pekerjaan Mustahil", data 27 dengan judul cerita "Abu Nawas Menjebak Pencuri", data 28 dengan judul cerita "emilih Jalan Kehutan yang Indah", data 32 dengan judul cerita "Raja Nyaris terbunuh", data 33 dengan judul cerita "Abu Nawas Ibu Sejati”, data 34

Struktur dan Kaidah Teks Anekdot dalam Kumpulan Cerita Abu Nawas 
dengan judul cerita "Tertipu Sendal ajaib", data 46 dengan judul cerita "Memenangkan Lomba Berburu", data 48 dengan judul cerita "Menampar Pipi raja", data 49 dengan judul cerita "Abu Nawas Hamil dan Melahirkan", data 50 dengan judul cerita "Abu Nawas Menduduki singasana raja", data 51 dengan judul cerita "Abu Nawas dan Pukulan Jadi Dinar", data 52 dengan judul cerita "Belajar dari Buah Arbei", data 55 dengan judul cerita "Abu Nawas Merayu Tuhan", dan data 57 dengan judul cerita "Air Susu yang Pemalu".

Berikut rekapitulasi mengenai kebahasaan yang terdapat pada cerita Abu Nawas. Lebih jelas bisa dilihat pada tabel 2 berikut ini.

Tabel 2. Rekpitulasi Kaidah Kebahasaan Teks Anekdot Pada Cerita Abu nawas.

\begin{tabular}{|l|l|l|}
\hline No & $\begin{array}{l}\text { Kaidah Kebahasaan } \\
\text { Teks Anekdot }\end{array}$ & Presentasi \\
\hline 1. & Waktu Lampau & $79 \%$ \\
2. & Pertanyaan Retorik & $52 \%$ \\
3. & Konjungsi Temporal & $98 \%$ \\
4. & Kata Kerja Material & $86 \%$ \\
5. & Kalimat Perintah & $62 \%$ \\
\hline \multicolumn{2}{|r|}{ Rata-rata } & $75 \%$ \\
\hline
\end{tabular}

Berdasarkan tabel rekapitulasi kaidah kebahasaan teks anekdot pada kumpulan cerita Abu Nawas di atas diperoleh nilai ratarata $75 \%$ memiliki kaidah kebahasaan yang lengkap. Pada bagian waktu lampau diperoleh nilai $79 \%$, bagian pertanyaan retorik diperoleh nilai 52\%, bagian konjungsi temporal diperoleh nilai $98 \%$, bagian kata kerja material diperoleh nilai $86 \%$ dan bagian kalimat perintah diperoleh nilai $62 \%$.

\section{SIMPULAN}

Hasil penelitian ini ialah pertama, struktur teks anekdot pada cerita Abu Nawas terdapat 44 teks anekdot yang terbentuk dari struktur teks anekdot secara sempurna dan 14 data yang tidak memiliki struktur teks anekdot yang tidak sempurna. struktur teks anekdot pada cerita Abu Nawas diperoleh nilai ratarata 94\% memiliki Struktur yang lengkap Struktur sempurna artinya teks anekdot tersebut terdiri dari abstraksi, orientasi, krisis, reaksi, dan koda sebagai pembentuk alur cerita suatu teks anekdot. Kedua, kaidah kebahasaan anekdot yang terdapat dalam Cerita Abu Nawas ditemui 19 data yang lengkap dan 39 data yang tidak lengkap. Kaidah kebahasaan teks anekdot pada kumpulan cerita Abu Nawas diperoleh nilai rata-rata $75 \%$ memiliki kaidah kebahasaan yang lengkap.

\section{REFERENSI}

Departemen Pendidikan Nasional. (2008). Panduan Pengembangan Bahan Ajar. Jakarta: Kemendikbud.

Dyah, E., Rustono, W., \& Nuryatin, A. (2017). Analisis Teks Anekdot Bermuatan Karakter dan Kearifan Lokal sebagai Pengayaan Bahan Ajar Bahasa Indonesia di SMA. Jurnal Pendidikan Bahasa Dan Sastra Indonesia, 6(2). https://doi.org/https://doi.org/10.15294/jp bsi.v6i2.23505

Heryadi, D. (2010). Metode Penelitian Pendidikan Bahasa. Bandung: PUSBILL.

Kemendikbud. (2013). Buku Guru Bahasa Indonesia untuk SMA/SMK/MAK Kelas $X$. Jakarta: Kementrian Pendidikan dan Kebudayaan Republik Indonesia.

Kemendikbud. (2016). Buku Guru Bahasa Indonesia untuk SMA/SMK/MAK Kelas X (Edisi Revisi 2016). Jakarta: Kementrian Pendidikan dan Kebudayaan Republik Indonesia.

Kosasih, E. (2014). Jenis-jenis Teks (Analisis Fungsi, Struktur, dan Kaidah serta Langkah Penulisannya). Bandung: Yrama Widya.

Mahsun. (2014). Teks Dalam Pembelajaran Bahasa Indonesia Kurikulum 2013. Jakarta: Rajawali Pers.

Mukhlis, M., \& Asnawi, A. (2019). Teks Anekdot dalam Cerita Lisan Yong Dollah Pewarisan Orang Melayu Sebagai Alternatif Pemilihan Bahan Ajar Bahasa Indonesia. GERAM, 7(2), 30-43. https://doi.org/10.25299/geram.2019.vol7 (2). 3774

Oktarisa. N, dkk. (2014). Pembelajaran memahami struktur dan kaidah teks anekdot siswa kelas x sma. Jurnal Kata (Bahasa, Sastra, Dan Pembelajarannya), 3(1), 1-13. Retrieved from Struktur dan Kaidah Teks Anekdot dalam Kumpulan Cerita Abu Nawas 
download.portalgaruda.org

Sobandi. (2013). Bahasa Indonesia untuk SMA/MA Kelas X. Jakarta: Erlangga.

Sugiyono. (2008). Metode Penelitian Pendidikan: Pendekatan Kuantitatif, Kualitatif, dan R\&D. Bandung: Alfabeta.

Yustinah. (2014). Produktif Berbahasa Indonesia SMA/MA Kelas X. Jakarta: Erlangga. 